\title{
Entre o psicodrama e a Gestalt-terapia: Encontros, obstáculos e perspectivas
}

Érico Douglas Vieira. Universidade Federal de Goiás. Luc Vandenberghe. Pontifícia Universidade Católica de Goiás.

\section{Resumo}

A divisão das psicoterapias em escolas e sistemas representa um desafio para o campo. Questionamos as dinâmicas de aproximação e de afastamento entre o Psicodrama e a Gestalt-terapia, a partir de entrevistas realizadas com 22 profissionais dessas abordagens. A pesquisa identificou um leque de condições facilitadoras e de obstáculos para o diálogo. Destacaram-se tanto a pessoa do profissional com suas necessidades e sua história singular, quanto a estrutura do campo e os processos sociais envolvidos. Os atrativos da integração incluem o enfrentamento de realidades clínicas complexas através de uma prática mais versátil, o refinamento teórico através do aproveitamento de conceitos externos e uma reflexividade mais madura proporcionada pelo encontro com o outro. Porém, emerge uma ligação íntima entre a identidade profissional do indivíduo e as características das abordagens e das comunidades profissionais que as sustentam. As forças que afastam o diálogo não podem ser compreendidas sem levar essas dinâmicas em consideração.

Palavras-chave: psicodrama; gestalt-terapia; psicologia clínica; interdisciplinaridade.

\begin{abstract}
Between psychodrama and gestalt therapy: Affinities, obstacles and perspectives. The fragmentation of psychotherapies in schools and systems is a challenge for the field. The present article examines the dynamics of attraction and repulsion between Psychodrama and Gestalt-therapy, based on interviews with 22 professionals of these approaches. The results identified a variety of conditions that either promote or hinder dialogue between the two of them. These referred both to the person of the professional with his or her needs and individual history, and to the structure of the professional area with its particular social processes. The attractions of psychotherapy integration include the need to deal with complex clinical realities through a more flexible practice, and the possibility for theoretical refinement through the encounter with the other. However, a close link emerged between professional identity and the features of theoretical models and of the professional communities that sustain them. The issues that hinder dialog remain unintelligible without considering these dynamics.
\end{abstract}

Keywords: psychodrama; gestalt-therapy; clinical psychology; interdisciplinarity.

\section{Resumen}

Entre psicodrama y terapia gestalt: Enlaces, obstáculos y perspectivas. La división de las psicoterapias en escuelas y sistemas es un desafío para el campo. Cuestionamos la dinámica de aproximación y diferenciación entre el Psicodrama y la Terapia Gestalt, a partir de entrevistas con 22 profesionales en estos enfoques. La investigación identificó una serie de obstáculos y condiciones facilitadoras para el diálogo. Los aspectos más destacados es la persona con sus necesidades profesionales y su historia única, y tambiém la estructura del campo y los procesos sociales involucrados. Las atracciones incluyen la integración para hacer frente a las realidades clínicas complejas a través de una práctica más versátil, el refinamiento teórico a través del uso de conceptos externos y una reflexión más madura que ofrece el encuentro con el otro. Sin embargo, surge una conexión íntima entre la identidad profesional del individuo y las características de los enfoques y las comunidades profesionales que los apoyan. Las fuerzas que impulsan el diálogo no se pueden entender sin tener en cuenta estas dinámicas.

Palabras clave: psicodrama; terapia gestalt; psicologia clinica; interdisciplinaridad. 
A organização do conhecimento psicoterápico em escolas e sistemas representa um desafio para o campo (Figueiredo, 2009). Historicamente, os líderes das abordagens enfatizaram mais a suposta superioridade da sua escola em relação às demais. Hoje ainda persiste o desinteresse pelo que as outras abordagens produzem (Norcross, 2005; Paris, 2013; Stricker \& Gold, 1996; Watchel, 2010). No campo das psicoterapias, percebem-se tendências que buscam aproximações entre abordagens e outras perspectivas que obstaculizam os diálogos.

O relacionamento com o outro é problemático entre as psicoterapias. Alguns psicoterapeutas parecem confinar a atenção somente para os temas tratados pela própria abordagem; o que está fora deste domínio restrito é tratado como se não existisse (Watchel, 2010). Nesta vertente, os profissionais pensam que não precisam estudar outras teorias e que cada abordagem deve prosseguir sua evolução isolada do mundo externo. Além disso, o pertencimento grupal a partir de uma comunidade de pensadores com afinidades fornece um suporte identitário e social que pode dificultar o reconhecimento dos méritos de outras teorias (Watchel, 2010). Como os grupos competem entre si por reconhecimento e prestígio, os aspectos singulares de cada escola são ressaltados em detrimento da busca de unidade (Norcross, 2005). A reputação de cada abordagem é construída baseada na promoção da novidade ou na reivindicação da especificidade (Paris, 2013). Como conseqüência, o espaço de convivência entre abordagens apresenta-se como um terreno repleto de hostilidades e rejeições em relação às contribuições do outro.

Em contraste, existe um crescente interesse de clínicos e pesquisadores em experimentar maneiras de se trabalhar com mais de uma abordagem (Norcross, 1997). Por que o psicoterapeuta deveria cultivar uma atitude de abertura para a diversidade teórica? Os desafios impostos pela atividade clínica, manifestados pela heterogeneidade da clientela e pela complexidade requerida na atuação do psicoterapeuta, impulsionam para o exame de técnicas, atitudes e conceitos de mais de uma abordagem. Além disso, os contatos entre as abordagens são considerados como caminhos para suscitar novas direções de pesquisas e como ajuda para melhorar o entendimento da própria escola através da visão de conceitos externos (Eubanks-Carter \& Burckel, 2005; Norcross, 1997).

Neste cenário, o Psicodrama e a Gestalt-terapia manifestam sinais de convergência, a despeito dos poucos estudos realizados para a investigação desta unidade.
Blatner (1996) menciona que a Gestalt-terapia absorveu a utilização de recursos dramáticos do Psicodrama. Almeida (2006) argumenta que as duas abordagens apresentam propostas co-irmãs, por possuírem uma visão fenomenológico-existencial das questões humanas.

Jacob Levy Moreno e Frederick Salomon Perls, criadores do Psicodrama e da Gestalt-terapia, respectivamente, participaram ativamente, no início do século $X X$, de movimentos expressionistas que formularam reações contra as normas burguesas e as ingênuas crenças no progresso (Wulf, 1998). Em Berlim, Fritz Perls estava envolvido com intelectuais e atores de teatro que propunham reformas sociais profundas de inspiração humanista e comunitária. Moreno, em Viena, era editor da revista expressionista Daimon, juntamente com Martin Buber, além de trabalhar com o teatro da Espontaneidade, que seria o embrião do Psicodrama (Sá-Júnior, 2009). As duas abordagens possuem como corolário o ideal de resgatar o potencial criativo do ser humano em face dos entraves impostos pela cultura que impedem a fluidez existencial (Vieira \& Vandenberghe, 2011). Na década de 1960, houve uma breve convivência acadêmica entre Moreno e Perls, posto que o criador da Gestalt-terapia participou de algumas sessões de Psicodrama dirigidas por Moreno. A partir desta incursão no Psicodrama, Perls buscou imprimir um cunho experiencial na sua abordagem, criando a técnica da cadeira vazia e adotando o uso de dramatizações com seus clientes (Blatner, 1996). Apesar deste ponto de unidade, as duas abordagens se desenvolveram separadamente. Tal fato pode ter se dado em função do quadro de rivalidade presente no campo das psicoterapias. No entanto, os espaços de convergências e divergências entre estas escolas convidam para uma investigação.

A partir de entrevistas com psicodramatistas e gestalt-terapeutas, pretendeu-se sondar a dinâmica interna de cada abordagem ao dar-se conta deste outro similar. No espaço de reflexão sobre a abordagem de filiação no encontro com a outra escola, os participantes foram questionados se e como estas escolas podem conviver e colaborar entre si.

\section{Método}

A teoria fundamentada nos dados foi utilizada no processo de investigação da análise da interface entre o Psicodrama e a Gestalt-terapia. Trata-se de uma metodologia qualitativa de coleta e interpretação dos dados, objetivando a construção de conceitos teóricos baseados nos próprios dados. O envolvimento simultâneo entre a coleta e a interpretação dos dados busca uma densidade 
conceitual, pretendendo ultrapassar o nível descritivo ao encontro de produções teóricas a respeito dos processos estudados (Charmaz, 2009). A interpretação é iniciada sem quadro conceitual preexistente. Esta opção, chamada de agnosticismo teórico configura a recusa do pesquisador de aderir precocemente a uma teoria já articulada ou a um modelo existente para estabelecer significados (Charmaz, 2009).

Entrevistas semi-estruturadas foram utilizadas para a coleta dos dados. Para obter um quadro vivo que abarcasse dimensões subjetivas, sociais e institucionais envolvidas nas possibilidades de diálogos entre as abordagens, optou-se pela escuta das narrativas de 11 psicodramatistas e 11 gestalt-terapeutas sobre o tema, sendo 14 mulheres (seis psicodramatistas e oito gestalt-terapeutas) e oito homens (cinco psicodramatistas e três gestalt-terapeutas). Foram entrevistados clínicos que têm proeminência na sua abordagem, alguns sendo pioneiros no âmbito regional e nacional. Dezessete são professores de formação na abordagem (sete de Psicodrama e 10 de Gestalt-terapia) e seis são professores universitários (cinco de Gestalt-terapia e um de Psicodrama). Por fim, oito são autores de livros na abordagem (três gestalt-terapeutas e cinco psicodramatistas). As questões que nortearam as entrevistas foram: a trajetória profissional e a percepção da própria abordagem; a percepção sobre a outra abordagem; o possível encontro entre as duas abordagens pela percepção de pontos em comum; as divergências entre as escolas; e as possibilidades de intercâmbios práticos e teóricos entre o Psicodrama e a Gestalt-terapia.

A partir das entrevistas transcritas, foram realizadas sucessivas reflexões entre a equipe de pesquisa para a construção de códigos analíticos que resultaram na emergência de conceitos teóricos fundamentados nos dados. As categorias construídas foram resultado da investigação das entrevistadas sem nenhuma adoção de hipótese ou a priori. A intenção era conhecer algo novo que pudesse emergir das narrativas dos psicodramatistas e gestalt-terapeutas. As percepções sobre a fronteira entre a abordagem de filiação e a outra escola foram o substrato para a construção de aspectos teóricos desde o início da investigação. No decorrer do processo, novos dados foram coletados com o objetivo de refinar ou aprofundar as questões apontadas inicialmente.

Neste percurso, quatro grandes categorias emergiram dos dados, demonstradas neste trabalho no item 3.1 "Visão, Vivência e Pragmática". Cada categoria representa aspectos importantes do processo de integração, além de apresentam uma densidade conceitual significativa. As categorias construídas foram: (1) Condições facilitadoras de integração; (2) Relação entre identidade e abordagem; (3) Obstáculos à integração e (4) Benefícios e caminhos para a integração. No Quadro 1, estão descritas as categorias e subcategorias construídas no processo de investigação da fronteira entre o Psicodrama e a Gestalt-terapia.

A combinação analítica de todas as categorias proporcionou leituras diferentes da análise separada de cada categoria. O presente artigo demonstra o modelo da dinâmica do jogo de aproximação e afastamento que emergiu da interligação dessas categorias.

\section{Resultados}

A apresentação dos resultados está organizada em torno de três eixos teóricos: (a) Visão, Vivência e Pragmática; (b) Pessoa e Campo e (c) Teoria, Ação e Reflexão. A partir dessas linhas, é possível retratar as condições do campo da integração entre o Psicodrama e a Gestalt-terapia.

As contribuições dos participantes são retratadas através da inserção de trechos de entrevistas. Os sujeitos são designados pelas letras $G$ para gestalt-terapeutas e $P$ para psicodramatistas, seguidas de números que indicam a ordem na qual foram entrevistados.

\section{Visão, vivência e pragmática}

A primeira categoria construída denominada "Condições facilitadoras de integração" engloba as percepções e reflexões sobre as características filosóficas da teoria de filiação e sua inserção na geografia das abordagens. Os aspectos filosóficos são importantes para escolhas válidas. Neste processo, os participantes detectam a abertura constitutiva da própria escola, como também os seus déficits. A mesma humildade que permite identificar lacunas na abordagem conduz, também, à percepção de que a prática já foi ampliada através de contribuições externas. No vislumbre da geografia das abordagens, a proximidade entre o Psicodrama e a Gestalt-terapia se insinua no espírito contido nas suas fundações e nos seus pressupostos filosóficos. Aspecto importante da filosofia da própria abordagem, a visão contextual de si e do outro é um exercício que prepara o terreno para os intercâmbios entre as abordagens.

A relação entre identidade e abordagem influencia o posicionamento frente ao diálogo. O caminho percorrido pelo profissional, inclusive seus acidentes de 
Entre o psicodrama e a Gestalt-terapia: Encontros, obstáculos e perspectivas

Quadro 1. Quadro de Categorias e Subcategorias da Fronteira entre o Psicodrama e a Gestalt-terapia

\begin{tabular}{|c|c|}
\hline Categoria & Subcategorias \\
\hline Condições facilitadoras de integração & 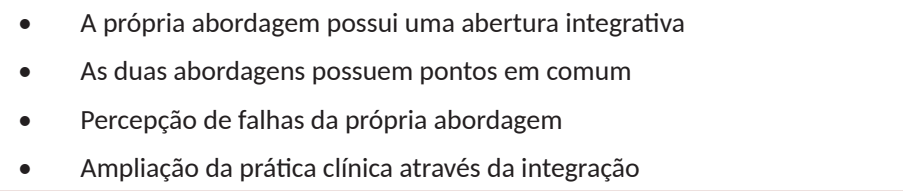 \\
\hline Relações entre identidade e abordagem & $\begin{array}{ll}\text { - } & \text { Vivências profissionais pró-integração } \\
\text { - } & \text { Vivências profissionais anti-integração }\end{array}$ \\
\hline Obstáculos à integração & $\begin{array}{l}\text { - } \\
\text { - } \text { A outra abordagem não pode complementar a minha } \\
\text { - } \\
\text { - }\end{array}$ \\
\hline Benefícios e caminhos para integração & $\begin{array}{ll}\text { - } & \text { Caminhos para a integração } \\
\text { - } & \text { Benefícios de integrações para as abordagens } \\
\text { - } & \text { Benefícios de integrações para a prática profissional }\end{array}$ \\
\hline
\end{tabular}

percurso, encontros, intercâmbios e vivências diversas, pode moldar uma prática de abertura a várias teorias. Uma sensação de enriquecimento pessoal e profissional emerge destas experiências. A seguir, exemplos de um entrevistado de cada abordagem relatando sua experiência de incursão na diversidade:

Então, eu passei por várias influências e certamente a Gestalt foi uma influência importante que marcou a minha linha de trabalho" (P14); "Eu estudo muito, leio muito, estudo tudo o que pode me ajudar a compreender mais o aspecto relacional do ser humano (G18).

Por outro lado, o investimento de paixão e admiração numa teoria que preenche necessidades pragmáticas e afetivas conduz a uma relação de harmonia entre a identidade pessoal e a identidade da abordagem. Os depoimentos a seguir demonstram uma significativa conexão entre aspectos subjetivos do psicoterapeuta e aspectos filosóficos e teóricos da abordagem. G6 fala sobre sua descoberta apaixonada: "Gente, é como todo mundo que descobre a Gestalt diz isso: sou eu! Sou eu, isso tem a ver comigo! É a Gestalt que me descobriu porque ela diz daquilo que eu acredito" (G6). P17 declara: "Eu era sonhadora e o Psicodrama me deu mais isto" (P17). G18 reflete sobre sua escolha: "Nessa trajetória, eu acho que chegar na Gestalt-terapia foi meio que achar o sapato que cabia no pé" (G18). G22 aponta a sua harmonia com a própria abordagem: "Para mim, a Gestalt continua sendo esse sapato hiper confortável, aquela roupa deliciosa que você veste, a sua segunda pele" (G22). Esta relação de encantamento pode tornar a abertura a outras ideias desnecessária ou, até mesmo, aversiva.
A categoria referente aos obstáculos à integração compreende os aspectos do campo que promovem o desenvolvimento de cada abordagem em separado. A luta por espaço e recursos representa um importante entrave para os intercâmbios fecundos. As comunidades das abordagens fornecem sustentação simbólica e financeira para seus membros, tais como identidade profissional, visibilidade pública, prestígio acadêmico e oportunidades de trabalho. A sobrevivência individual depende da defesa dos méritos da escola de filiação. A concorrência entre os grupos institucionais é fomentada pela definição de si, que pode ser construída em oposição ao outro que recebe desqualificações. A entrevistada P13 aponta a falta de uma metodologia de ação como fraqueza da Gestalt-terapia: "Como é importante a dramatização! E eu acho que a Gestalt, pelo menos os gestaltistas que eu conheço e vi trabalhar, eles trabalham sentados. Eles são muito limitados em relação à movimentação física, entendeu?" A entrevistada G2 classifica o Psicodrama como uma abordagem diretiva em contraposição à maior abertura da própria abordagem: "Quem interrompe é o terapeuta, na hora que ele julga que tem que interromper. Então, eu acho que o Psicodrama, ele tem uma postura mais autoritária, mais diretiva e menos fenomenológica". Assim, necessidades vitais se manifestam em um forte compromisso emocional com a abordagem, engendrado pela desconstrução do outro.

A última categoria reúne as percepções sobre os benefícios e critérios para os diálogos entre as teorias. A integração disciplinada como ação vital se refere à adoção de regras que legitimam os intercâmbios, que são considerados elementos essenciais para a desobstrução 
de impasses das teorias e instrumentos efetivos para formar identidades profissionais sólidas, que lidam com realidades complexas. O diálogo é o oxigênio do campo. Como não é possível viver isolado, os intercâmbios podem ser vitais. Com uma visão mais global do campo, cada abordagem é percebida como capaz de retratar somente pequenos fragmentos da realidade. Para alcançar olhares mais amplos, o trânsito entre várias conceitualizações requer flexibilidade e disciplina ao mesmo tempo. O entrevistado P10 reflete sobre os benefícios dos intercâmbios: "Dialogar com outras possibilidades e tal, a gente ganha novas perspectivas e com isso a gente pode ganhar novas formas de intervenção, né". Em outro momento, pondera sobre cuidados necessários na adoção da integração: "O que eu proponho é que em cada situação a gente faça uma avaliação da pertinência dessa interlocução desses campos ou não" (P10). A integração fundamentada em critérios é impulsionada pelas condições de abertura, incluindo-se as vivências profissionais pró-integração. Mesmo com a existência de obstáculos, a integração é uma realidade, manifestada na busca dos profissionais por outras teorias e pela influência recíproca constante entre abordagens. A integração, com seus obstáculos e condições facilitadoras, é retratada como um exercício perene do campo das psicoterapias.

\section{Pessoa e campo}

$\mathrm{Na}$ interação entre as categorias emergiram dois eixos que permitiram uma nova organização dos dados em função do campo profissional e das vivências individuais. A identidade e as vivências do psicoterapeuta facilitam ou dificultam a integração, em interação com as condições do campo profissional, que inclui as exigências do mercado e as agendas dos atores sociais. Juntas, as vivências e as necessidades individuais do clínico e as condições do campo organizam as dinâmicas da integração.

A pessoa do psicoterapeuta, com suas simpatias, antipatias, necessidades, faltas e idiossincrasias representa um fator muito relevante para as possibilidades de integração. Há condições do campo que direcionam, propulsionam, influenciam ou inibem a integração. Há uma influência marcante entre identidade e abordagem e as condições do campo. As condições do campo, incluindo a cultura clínica, o clima ideológico na classe profissional, nas universidades e nas instituições de formação, influenciam diretamente a relação entre identidade e abordagem. Estas condições do campo representam a matriz na qual é moldada a identidade profissional e a afiliação à abordagem.
$\mathrm{Na}$ área de contato entre fatores pessoais e do campo que inibem ou facilitam os intercâmbios, são reconhecidas perspectivas coletivas que bloqueiam a diversidade e os caminhos individuais que a buscam. A facilidade de estabelecer pontes entre teorias, a curiosidade intelectual e a busca do aprimoramento representam perspectivas individuais que incentivam o contato com outras escolas. A postura de abertura a várias conceitualizações é enaltecida por P13: "A minha maior diferença é que me recuso a ficar restrita por qualquer sistema teórico, o ser humano é tão complexo que acho que precisamos de todos para ajudá-lo" (P13). As vivências que enclausuram os profissionais na abordagem de filiação se vinculam às questões de pertencimento grupal, através das pressões institucionais para a expressa fidelidade à abordagem. Este cenário aponta para uma contradição do campo. Os profissionais anseiam pela diversidade, mas são constrangidos por estruturas coletivas. Pode-se perceber uma articulação entre a categoria dos obstáculos à integração e a categoria que engloba os possíveis benefícios da integração. Um desejo em vivenciar os benefícios do trânsito na diversidade teórica convive com realidades institucionais que bloqueiam as possibilidades de circulação. P15 aponta as dificuldades em transitar entre diferentes espaços de formação: "Eu já participei de vários grupos, tem as turminhas...O pessoal do Psicodrama me viu lá no Sedes e me perguntaram se eu estava dando aula e eu respondi que estava estudando Gestalt. Eles fizeram uma cara..." Desta forma, se o profissional deseja estudar mais de uma abordagem, deve ter consciência de que precisa seguir um caminho pessoal sem incentivo ou, até mesmo, com a reprovação dos espaços institucionais competitivos.

\section{Teoria, ação e reflexão}

A articulação entre teoria e prática profissional foi um significativo eixo compreensivo que emergiu dos dados. Pode-se tomar como perspectiva para pensar a integração, seus limites e desafios, ora a prática profissional, ora os aspectos teóricos. Estas dimensões permitiram outro reagrupamento e outra leitura dos dados.

O tema da integração é bastante significativo na prática profissional. Os imperativos da prática requerem o estudo de outras abordagens para capacitar o profissional em face da diversidade de experiências. Os psicodramatistas e gestalt-terapeutas construíram sua identidade profissional a partir do estudo de diversas teorias, aspecto que refinou o olhar clínico, ampliou as possibilidades de intervenção de cada um, mantendo a 
afiliação à abordagem escolhida. A relação entre identidade e abordagem, descrita na segunda categoria, retrata a importância da formação de uma identidade profissional sólida para que o psicoterapeuta se sinta seguro e competente na práxis clínica. O pertencimento dos profissionais às comunidades científicas é um importante aspecto da prática profissional, que interfere nas possibilidades de exercício integrativo. Além dos compromissos emocionais decorrentes do pertencimento, há uma delimitação de temas científicos dignos de interesse, com o descarte de vários temas marginais. 0 profissional participa de um campo que condiciona suas reações perante teorias externas. Geralmente, esta estrutura coletiva e institucional, motivada pela disputa de mercado, inibe mais do que estimula o estudo de outras escolas. Por exemplo, G7 aponta os prejuízos do enclausuramento: "As abordagens precisam ser influenciadas por outras para crescerem. A abordagem que se fecha em si... Você acaba não conseguindo ler um trabalho das pessoas porque você não entende".

Os aspectos teóricos das abordagens também é um eixo compreensivo importante. A abertura integrativa das escolas encoraja a busca por novas integrações. Pode-se tomar como perspectiva a pertinência da integração entre duas abordagens em relação seus aspectos epistemológicos. As similaridades facilitam o diálogo, excetuando-se quando há falhas em comum que desestimulam o interesse pela integração. A coerência epistemológica é considerada um critério que autoriza as integrações, conforme pondera P10: "É preciso investigar se os campos apontam na direção de uma sinergia possível; aí, há uma troca possível". Estas regras que podem nortear os diálogos entre abordagens emergiram na categoria dos benefícios e critérios para a integração e demonstram que a integração não precisa ter uma conotação negativa de desorganização, necessariamente. A reflexão e a ação sobre a integração podem ser consideradas processos simultâneos. Os entrevistados valorizam a ponderação racional como operação fundamental nos intercâmbios integrativos. Para P17, a integração deve ser feita considerando-se os pressupostos filosóficos das abordagens envolvidas: "Nas técnicas pode dar essa falsa impressão que é parecido, que é muito igual, mas primeiro eu acho que você tem que olhar a epistemologia e correr atrás desses filósofos, ver o que eles estão falando". Há uma preocupação com as possibilidades de criação de produtos integrativos desorganizados, o que pode empobrecer as abordagens. As condições do campo que alimentam a rivalidade podem desencorajar ou frear o ímpeto para a integração, o que pode proteger a singularidade de cada escola.

Estes dois eixos compreensivos permitem diferentes tomadas de perspectivas sobre a integração que interferem na prática profissional, contribuindo para aprimorá-la ou encerrando os profissionais em grupos fechados. Os profissionais podem ficar conscientes do prejuízo decorrente do isolamento e dos benefícios para a prática ao estudar outras teorias. Os corpos teórico e metodológico das abordagens podem evoluir ou serem empobrecidos no processo integrativo. Estas duas dimensões podem direcionar novas pesquisas sobre o tema da integração, seja para subsidiar a prática dos psicoterapeutas, seja para contribuir para o aprimoramento das escolas e, por fim, para evitar processos integrativos incoerentes.

A integração é um exercício que envolve reflexão e ação e pode ser concebida como um processo gradativo contendo estágios. A aproximação e os intercâmbios entre abordagens se intensificam na evolução deste processo. Neste sentido, a interação entre as categorias "Condições facilitadoras de integração" e "Benefícios e caminhos para a integração" possibilita o vislumbre de etapas do processo de integração. Examinar reflexivamente e contextualmente a si mesmo e ao outro prepara o terreno para o diálogo, contribuindo para quebrar barreiras. A categoria 4 representa um processo mais avançado em direção aos diálogos, com reflexões mais apuradas sobre o processo integrativo, suas vantagens e regras necessárias. A categoria 1, que retrata o olhar reflexivo dirigido à abordagem em função do campo, representa uma etapa de pré-integração. Primeiramente, são necessárias atitudes de abertura do campo para, então, os intercâmbios serem realizados. Estes estágios do processo de integração entre a Gestalt-terapia e o Psicodrama podem balizar, também, a compreensão de diálogos entre outras abordagens.

As ponderações sobre os intercâmbios suscitaram reflexões nos participantes sobre os limites e as potencialidades da escola de filiação. Examinar outro sistema e possíveis interseções possibilitou um olhar analítico voltado para a abordagem de filiação. P10 valoriza o diálogo como possibilidade de refinar o olhar sobre si mesmo: "Conhecer outros autores, outras possibilidades ajuda, pode ajudar. Na verdade, é esse o caminho pra gente olhar pra gente mesmo". A constituição da abordagem através da assimilação de conceitos, suas limitações atuais, pensar nas similaridades com outras teorias e refletir sobre os benefícios da integração são 
operações que facilitam um olhar crítico em relação à escola de filiação. As principais virtudes teóricas e metodológicas e as lacunas ficam mais claras no processo dialógico entre as teorias. Ensimesmar-se pode obscurecer a visão. Olhar as outras abordagens funciona como um exercício especular no qual a abordagem de filiação pode ser problematizada. Os compromissos ideológicos e as linhas de investigação podem ser revistos.

\section{Discussão}

No decorrer do processo de investigação, os aspectos emergentes no exame da interface entre o Psicodrama e a Gestalt-terapia apresentaram aspectos diferentes das expectativas iniciais. A escuta dos profissionais das duas abordagens possibilitou uma ampliação do tema da integração para além de aspectos racionais, acadêmicos ou teóricos. Além da análise das convergências, divergências e intercâmbios entre as abordagens, outras questões significativas puderam ser mapeadas. A relação subjetiva do profissional com as teorias psicológicas, as dinâmicas grupais e sociais das comunidades científicas e a articulação entre teoria e prática diante dos desafios da psicoterapia foram achados que demonstram a realidade viva presente no manejo com os saberes psicológicos.

As abordagens psicológicas adotam uma abertura integrativa, pois são constituídas por meio da assimilação de conceitos de outras escolas. Os participantes percebem tal condição como uma abertura que caracteriza o campo das psicoterapias e que convida à realização de novas integrações. Eles constatam a vitalidade potencial dos diálogos, pois tanto a formação quanto o atual desenvolvimento das abordagens são possibilitados pela incorporação de conceitos externos. Há a constatação de que o interesse em integração tem contribuído para o refinamento das teorias sobre o processo psicoterapêutico (Eubanks-Carter \& Burckel, 2005).

De acordo com Morin (2007), muitos progressos realizados nas ciências se deram graças à circulação de conceitos e a consequente desobstrução das disciplinas. A assimilação de conceitos de outras teorias permitiu o advento de novas abordagens em psicoterapia. Por exemplo, o espírito de fundação do Psicodrama e da Gestalt-terapia tinha a integração como realidade fundamental. A Gestalt-terapia pode ser entendida como uma integração bem realizada de conceitos oriundos de trabalhos experimentais como a Psicologia da Gestalt, a Teoria de Campo e a Teoria Organísmica transpostos para a práxis psicoterápica (Frazão \& Fukumitsu, 2013; Lima, 2013; Ribeiro, 1985; Rodrigues, 2013). O Psicodrama concretiza a busca de Moreno em trazer idéias e conceitos do teatro para promover a espontaneidade de indivíduos, grupos e instituições (Contro, 2011; Moreno, 1975). Para Bourdieu (2008), as inovações nas ciências geralmente ocorrem nas interseções. Desta forma, ter consciência de que os intercâmbios de conceitos constituem uma realidade pode ajudar os pesquisadores a assimilar criteriosamente recursos externos para o desenvolvimento de determinada abordagem.

A constatação de que a prática clínica pode ser ampliada representa uma vivência profissional pró-integração e abre caminho para o enaltecimento dos benefícios para a prática profissional. Para lidar com a complexidade da realidade clínica, os profissionais reconhecem que outros sistemas têm contribuições significativas. A reflexividade sobre as limitações da própria abordagem pode quebrar a atitude de autossuficiência e promover uma abertura ao diálogo entre escolas. Assim, há a vivência do estudo de diversas teorias como uma atitude que fornece segurança e sensação de competência em face da complexidade da realidade. Norcross (1997) pondera que uma das buscas dos pesquisadores interessados na integração é aumentar o repertório de técnicas e estratégias do psicoterapeuta. A integração entre abordagens geralmente é proposta como via para se alcançar intervenções mais eficazes (Gold \& Stricker, 2006; Lemmens, Ridder, \& Lieshout, 1994; Norcross, 2005; Stricker \& Gold, 1996). Alguns outros estudos sugerem que os psicoterapeutas se concentram primariamente em uma ou duas abordagens e, ao mesmo tempo, tentam extrair de outras escolas, em menor grau, aspectos úteis para sua prática (Norcross \& Halgin, 2005). Safran e Messer (1997) argumentam que a formação dos terapeutas deveria contemplar mais de uma maneira de praticar a psicoterapia. Os participantes da pesquisa se sentem confortáveis ao pautar sua identidade em uma abordagem e alimentar sua curiosidade intelectual com outros conhecimentos ao mesmo tempo. Existe um desejo de uma maior liberdade para transitar entre vários saberes que vislumbra benefícios para o enfrentamento de realidades clínicas complexas.

Em contraste, há uma corrente de pensamento entre os participantes de que as abordagens devem tentar resolver por si mesmas suas limitações, sem assimilar os recursos das outras escolas. Recorrer à ajuda externa seria uma demonstração de fraqueza. Esta atitude de autossuficiência pode ser entendida como uma força que afasta as possibilidades de diálogos entre abordagens. Alguns participantes reconhecem a influência de 
processos sociais que influenciam o enclausuramento em guetos teóricos. Os valores pessoais coincidem com os pressupostos filosóficos da escola, produzindo uma forte identificação do profissional. Há uma idealização da própria escola que leva ao desinteresse em buscar recursos externos. Esta relação de pertencimento pode originar obstáculos à integração. O pertencimento a um grupo de pensadores afins fornece um suporte social que dificulta ao profissional estar ciente de que participa de um processo que limita sua visão das outras abordagens (Watchel, 2010). Na disputa por recursos, os membros das comunidades rivalizam entre si na reivindição de superioridade. As diferenças são realçadas para a promoção da originalidade, singularidade e superioridade (Paris, 2013). O público deve ser convencido a consumir conceitos e serviços de determinada abordagem em detrimento das outras.

As controvérsias entre abordagens não são de natureza teórica ou empírica como era de se esperar em um debate intelectual e científico. A hostilidade é dirigida para as outras abordagens, que se tornam alvo de desqualificações. Neste discurso, observa-se o confronto com o outro. Como ocorre nos casos de discriminações étnicas e raciais, cada abordagem procura se definir em comparação com um outro desprezado. A alteridade é massacrada para consagrar a superioridade da própria escola (Safran \& Messer, 1997).

Para a construção da reputação profissional ou para a promoção de determinada abordagem, há a ênfase ao que é novo ou diferente (Norcross, 2005). As forças que afastam as abordagens se manifestam através de críticas metodológicas e teóricas dirigidas ao outro, mas possuem um cerne mais profundo relacionado a questões de identidade grupal e disputa por recursos (Watchel, 2010). As necessidades emocionais e pragmáticas impedem a apreciação dos méritos do outro. Desta forma, o debate sobre os intercâmbios entre abordagens não pode ser centrado somente em aspectos racionais ou teóricos, sob pena de não serem mapeadas adequadamente as forças presente nas fronteiras entre abordagens e os elementos envolvidos na relação dos pesquisadores e psicoterapeutas com os saberes psicológicos.

Os distanciamentos e divergências atuantes na fronteira entre o Psicodrama e a Gestalt-terapia apontam que a rivalidade presente pode ser alimentada pela disputa pelo mesmo nicho de mercado. As semelhanças filosóficas e metodológicas colocam as abordagens em espaço de proximidade no âmbito geral da geografia das psicoterapias. Para a obtenção de prestígio e de clientela, tendo em vista a proximidade das fronteiras, as virtudes são atribuídas à própria abordagem e os defeitos são projetados para a outra escola. Tal processo se assemelha ao narcisismo das pequenas diferenças descrito por Freud (1930). Grupos que compartilham territórios adjacentes geralmente se envolvem em disputas constantes, adotando estereótipos e ridicularizando-se uns aos outros. Nesta perspectiva, o compartilhamento de fronteiras pode ensejar o direcionamento da agressividade para a outra abordagem, o que pode promover uma coesão no próprio grupo.

Apesar da aparente contradição, os obstáculos contidos nas narrativas dos participantes também podem nortear os caminhos para a integração. A possibilidade de empobrecimento das abordagens através da integração pode servir de alerta para a construção de caminhos integrativos enriquecedores. A atenção à distância epistemológica entre duas escolas, a preservação das especificidades valiosas do próprio sistema e o exame cuidadoso das possibilidades e dos objetivos de diálogo são diretrizes pertinentes à integração (Norcross, 2005; Safran \& Messer, 1997). Na perspectiva dos participantes, a proximidade epistemológica é um importante critério que pode autorizar as integrações. As abordagens que possuem uma relativa unidade em termos de fundamentos filosóficos e metodológicos teriam um caminho facilitado para os intercâmbios. Safran e Messer (1997) compreendem que a proximidade epistemológica abre caminho para a cooperação entre abordagens, pois promove uma sensação de familiaridade e diminui a sensação de estranheza do outro. Outra diretriz presente nos dados compreende que cada abordagem possui pontos fechados e pontos abertos para os diálogos. Baseado nisto, pode-se pensar que determinadas abordagens em comparação possuem algumas áreas de concordância e outros pontos de distanciamento.

A percepção de pontos em comum entre as abordagens é uma condição promotora que pode indicar um caminho para a integração. Similaridades na visão de homem podem facilitar o estabelecimento de pontes. A busca de similaridades pode, ainda, contribuir para melhorar a cooperação entre escolas rivais, ao diminuir a ênfase nas divergências (Norcross, 1997). No caso do Psicodrama e da Gestalt-terapia, os pontos de unidade - uso de recursos dramáticos, influência de pressupostos fenomenológico-existenciais e ênfase nos processos criativos - facilitam o diálogo (Almeida, 2006; Sá-Júnior, 2009). As duas abordagens dão ênfase ao crescimento humano através da ativação de suas potencialidades, ao invés da 
busca de cura de sintomas (Frazão \& Fukumitsu, 2013; Moreno, 1975). Para Ribeiro (1985), "a Gestalt-terapia se coloca ao lado das psicoterapias humanísticas, o que significa que contém e promove a ideia do homem como centro, como valor positivo, como capaz de autogerir e regular-se"(p. 29). Os participantes perceberam afinidades no âmbito das estratégias metodológicas, especialmente na maneira como a psicoterapia é conduzida. As duas abordagens possuem concepções semelhantes sobre o processo de mudança. Os pontos mais citados foram: a ênfase na experiência presente do cliente, a valorização do trabalho com grupos, a busca da vivência que mobilize outros recursos além do material verbal e a busca de uma horizontalidade na relação terapêutica. Esta unidade mapeada está em sintonia com as visões de Almeida (2006) e Blatner (1996), que também percebem afinidades na visão de homem entre o Psicodrama e a Gestalt-terapia.

Portanto, a partir dos depoimentos de gestalt-terapeutas e psicodramatistas, é possível perceber as forças que estimulam as integrações e os entraves e as contra-indicações para os intercâmbios entre escolas no cenário da integração. Para a análise destas forças, é preciso levar em consideração os aspectos pessoais do psicoterapeuta, os aspectos epistemológicos das abordagens, a intensa competição por recursos materiais e simbólicos no campo das psicoterapias, as características grupais e institucionais das escolas, bem como os contornos complexos da prática profissional. As reflexões sobre cada escola em função do campo, a humildade de recorrer ao outro e os caminhos pessoais percorridos na diversidade teórica são forças que impulsionam a integração. As disputas de mercado e o forte compromisso emocional dos membros de cada comunidade científica desestimulam os intercâmbios. A vitalidade dos intercâmbios fica impedida de ser atualizada neste cenário competitivo. Será que é possível abandonar as atitudes de rivalidade e abrir mão das disputas por recursos? É possível que as abordagens floresçam e os profissionais conquistem espaço a partir de uma lógica não competitiva? Por outro lado, os entraves à integração podem moderar o ímpeto dos integracionistas, estimulando ponderações sobre diretrizes para a realização de diálogos bem sucedidos. O que se pode deduzir é que a prescrição central dos participantes é que a integração seja realizada de forma sistematizada como condição necessária para o enriquecimento profissional e teórico. O campo das psicoterapias precisa ser menos competitivo para o incremento de uma maior comunicação entre as abordagens (Norcross, 2005; Paris, 2013, Watchel, 2010).

\section{Considerações finais}

A unidade entre o Psicodrama e a Gestalt-terapia pode preparar o terreno para que os membros de cada abordagem procurem conhecer de que forma as similaridades são desenvolvidas na outra escola. Este exercício especular pode fornecer subsídios para a prática clínica dos psicoterapeutas e, ainda, colaborar para refinar os aspectos teóricos da abordagem de filiação. A análise das divergências pode contribuir para a complementaridade entre as disciplinas, ao evidenciar as lacunas e as necessidades de cada sistema, que podem ser superadas com a ajuda do outro.

O contato entre as ciências, semelhante ao contato entre civilizações, possibilita a manifestação das disposições implícitas, dos compromissos ideológicos dos grupos e das omissões epistemológicas. Nos diálogos sistematizados, ao invés de cumprir o receio comum de geração de produtos desorganizados e práticas incoerentes, a integração em psicoterapia pode instaurar um processo de reflexividade de cada escola. O intercâmbio de conceitos e de atitudes clínicas pode colaborar para desobstruir entraves causadores de impasse no desenvolvimento de cada abordagem e para empoderar o profissional perante a diversidade da prática. A presente pesquisa indica que é considerável o desafio para a dissolução dos preconceitos e das barreiras em relação à integração, pois as disputas de mercado entre as abordagens alimentam um clima de forte competição. Se o campo das psicoterapias conseguir superar esta lógica, os profissionais se veriam mais livres para sondar mais de uma forma de pensar sua prática.

\section{Referências}

Almeida, W. C. (2006). Psicoterapia aberta. O método do psicodrama, a fenomenologia e a psicanálise. São Paulo: Àgora.

Blatner, A. (1996). Uma visão global do psicodrama: fundamentos históricos, teóricos e práticos. São Paulo: Àgora.

Bordieu, P. (2008). Para uma sociologia da ciência. Lisboa: Edições 70.

Charmaz, K. (2009). A construção da teoria fundamentada: guia prático para análise qualitativa. Porto Alegre: Artmed.

Contro, L. (2011). Psicossociologia crítica: a intervenção psicodramática. Curitiba: CRV.

Eubanks-Carter, C., \& Burckel, L. A. (2005). Future directions in Psychoterapy Integration. In M. R. Goldfried \& J. C. Norcross (Orgs.), Handbook of psychotherapy integration (pp. 503-521). Nova lorque: Oxford University Press. 
Entre o psicodrama e a Gestalt-terapia: Encontros, obstáculos e perspectivas

Figueiredo, L. C. M. (2009). Revisitando as psicologias. Da epistemologia à ética das práticas e discursos psicológicos. Petrópolis: Vozes.

Frazão, L. M., \& Fukumitsu, K. O. (2013). Gestalt-terapia: fundamentos epistemológicos e influências filosóficas. São Paulo: Summus.

Freud, S. (1930[1929]). O mal-estar na civilização. In Edição standard brasileira das obras psicológicas completas de Sigmund Freud (v. 21, pp. 75-171). Rio de Janeiro: Imago

Gold, J., \& Stricker, G. (2006). Introduction: an overview of psychotherapy integration. In G. Stricker \& J. Gold, (Orgs), A casebook of psychoterapy integration (pp. 03-16). Washington, DC: American Psychological Association.

Lemmens, F., Ridder, D. De, \& Lieshout, P. V. (1994). The integration of psychotherapy: Goal or utopia? Journal of Contemporary Psychotherapy, 24(4), 245-257. doi: 10.1007/BF02310273

Lima, P. V. A. (2013). A Gestalt-terapia holística, organísmica e ecológica. In M. M. Frazão \& K. O. Fukumitsu (Orgs.), Gestalt-terapia: fundamentos epistemológicos e influências filosóficas (pp. 145-156). São Paulo: Summus.

Moreno, J. L. (1975). Psicodrama. São Paulo: Cultrix.

Morin, E. (2007). Introdução ao pensamento complexo. Porto Alegre: Sulina.

Norcross, J. C. (1997). Emerging breakthroughs in psychotherapy integration: Three predictions and one fantasy. Psychoterapy, 34(1), 86-90. doi: $10.1037 / \mathrm{h} 0087757$

Norcross, J. C. (2005). A Primer on psychotherapy integration. In J. C. Norcross \& M. R. Goldfried (Orgs.), Handbook of psychotherapy integration (pp. 3-23). Nova lorque: Oxford University Press.

Norcross, J., \& Halgin, R. (2005). Training in psychoterapy integration. In J.C. Norcross \& M. R. Goldfried (Orgs.), Handbook of psychotherapy integration (pp. 439-458). Nova lorque: Oxford University Press.
Paris, J. (2013). How the history of psychotherapy interferes with integration. Journal of Psychotherapy Integration, 23(2), 99-106. doi: $10.1037 / a 0031419$

Ribeiro, J. P. (1985). Gestalt-terapia: refazendo um caminho. São Paulo: Summus.

Rodrigues, H. E. (2013). Relações entre a teoria de campo de Kurt Lewin e a Gestalt-terapia. In M. M. Frazão \& K. O. Fukumitsu (Orgs.), Gestaltterapia: fundamentos epistemológicos e influências filosóficas (pp. 114-144). São Paulo: Summus.

Safran, J. D., \& Messer, S. B. (1997). Psychotherapy integration: A postmodern critique. Clinical Psychology: Science and Practice, 4(2), 140-152. doi: 10.1111/j.1468-2850.1997.tb00106.x

Sá-Júnior, L. F. C. (2009). Gestalt, literatura e "literatura gestáltica": expressionismo, contracultura e narrativas autobiográficas. Revista IGT na Rede, 6(10), 29-46. Recuperado de http://www.igt.psc.br/ ojs/viewarticle.php?id=231

Stricker, G., \& Gold, J. R. (1996). Psychotherapy integration: An assimilative, psychodynamic approach. Clinical Psychology: Science and Practice, 3(1), 47-58. doi: 10.1111/j.1468-2850.1996.tb00057.x

Vieira, E. D., \& Vandenberghe, L. (2011). Reflexões sobre Gestalt-terapia e Psicodrama a partir do movimento de integração em psicoterapia. Revista da Abordagem Gestáltica, 17(1), 75-84. Recuperado de http://pepsic.bvsalud.org/scielo.php?script=sci_arttext\&pid=S1809$68672011000100011 \&$ Ing=pt\&tlng=pt

Wachtel, P. L. (2010). Psychotherapy integration and integrative psychotherapy: Process or product? Journal of Psychotherapy Integration, 20(4), 406-416. doi: 10.1037/a0022032

Wulf, R. (1998). The historical roots of Gestalt Therapy Theory. The Gestalt Journal, 21(1), 81-96. Recuperado de http://www.gestalt. org/wulf.htm

Érico Douglas Vieira, Doutor em Psicologia pela Pontifícia Universidade Católica de Goiás, é Professor Adjunto na Universidade Federal de Goiás - Regional Jataí. Endereço para correspondência: Rua Dona Esmeralda, 606 - Vila Fátima - Jataí - GO. CEP: 75803-095.

Telefone: (64) 3606-8127. E-mail: ericopsi@yahoo.com.br

Luc Vandenberghe, Doutor em Psicologia Clínica pela Université de Liêge (ULg) Bélgica, é Professor na Pontifícia Universidade Católica de Goiás. E-mail: luc.m.vandenberghe@gmail.com 